Luciana Mello Ribeiro

PROFESSORES UNIVERSITÁRIOS:

SEUS VALORES E A OPÇÃO DA EDUCAÇÃO AMBIENTAL

Tese de Doutorado

Tese apresentada ao Programa de Pós-graduação em Educação Brasileira da PUC-Rio como requisito parcial para obtenção do título de Doutor em Educação.

Orientadora: Hedy Silva Ramos Vasconcellos 


\title{
PROFESSORES UNIVERSITÁRIOS: SEUS VALORES E A OPÇÃO DA EDUCAÇAO AMBIENTAL
}

Tese apresentada como requisito parcial para obtenção do grau de Doutor pelo Programa de Pós-graduação em Educação do Departamento de Educação do Centro de Teologia e Ciências Humanas da PUC-Rio. Aprovada pela Comissão Examinadora abaixo assinada.

\author{
Profa. Hedy Silva Ramos de Vasconcellos \\ Orientadora \\ PUC-Rio
}

Profa. Tânia Dauster Magalhães e Silva $^{\text {PUC-Rio }}$
PUa

Prof $^{\mathrm{a}}$ Maria de Lourdes Spazziani

Universidade Estadual Paulista Júlio de Mesquita Filho

Prof $^{a}$ Diva Lopes da Silveira

Universidade Federal Rural do Rio de Janeiro - UFRRJ

Prof. Vilson Sérgio de Carvalho

Universidade Cândido Mendes
Prof $^{\circ}$ PAULO FERNANDO CARNEIRO DE ANDRADE
Coordenador Setorial do Centro
Teologia e Ciências Humanas - PUC-Rio

Rio de Janeiro, I 
Todos os direitos reservados. É proibida a reprodução total ou parcial do trabalho sem autorização da universidade, da autora, e do orientador.

\section{Luciana Mello Ribeiro}

Graduou-se em Ciências Biológicas pela UNESP (1995), é especialista em Meio Ambiente (1997), mestre em Educação Brasileira pela PUC-Rio (2003). Sua área de pesquisa é a Educação Ambiental, tendo desenvolvido diversos projetos e artigos, organizado e participado de eventos na área. Atua também em programas de pósgraduação, inclusive no formato educação à distância.

FICHA CATALOGRÁFICA

Ribeiro, Luciana Mello

Professores universitários : seus valores e a opção da educação ambiental / Luciana Mello Ribeiro ; orientadora: Hedy Silva Ramos Vasconcellos. - 2008.

309 f. : il. ; $30 \mathrm{~cm}$

Tese (Doutorado em Educação)Pontifícia Universidade Católica do Rio de Janeiro, Rio de Janeiro, 2008.

Inclui bibliografia

1. Educação - Teses. 2. Educação ambiental. 3. Docentes universitários. 4. 
Aos que desejam se renovar para melhor e renovando-se renovam também ao mundo.

Aos que, fazendo o melhor que podem, ainda conseguem ampliar sua lucidez e através dela se reposicionarem na grande espiral evolutiva que é a vida, atualizando-se para si mesmos e para todos aqueles com quem tenham tido ou mantenham relações. 


\section{Agradecimentos}

Em breves linhas pouco se traduz dos memoráveis e providenciais auxílios que recebi durante a feitura desta tese. Procurarei me ater à menção do imprescindível, ficando aqui registrado que meu reconhecimento vai muito além destas palavras e nomes principais. Há necessidade da informalidade para melhor expressar estes agradecimentos.

Gratidão, de acordo com o Houaiss, significa "reconhecimento de uma pessoa por alguém que lhe prestou um benefício, um auxílio, um favor etc.; agradecimento”. Falar sobre os benefícios reconhecidos é insuficiente para expressar os pequenos e grandes favores que devo a tantos colaboradores. De modo que me vejo obrigada a contar com a compreensão de quem me lê para com a limitação das palavras.

Em primeiríssimo lugar minha gratidão a minha orientadora, Hedy Vasconcellos e à coordenação da Pós-Graduação, na pessoa de Rosália Duarte, que souberam compreender os desafios e percalços pelos quais passei, temperando seu auxílio com as doses necessárias de solidariedade e firmeza. Aos demais professores e aos colegas, sou grata pelo conhecimento compartilhado e por abrirem novas trilhas em meu pensamento. À banca examinadora, pela atenção e cuidado.

Ao Marcos, agradeço a partilha dos doze anos de aprendizado mútuo.

Devo muito de minha saúde ao amparo de minha fonoterapeuta, Regina Camillo, cuja intervenção lúcida e acolhedora tem sido importante apoio. A você meu carinho e reconhecimento. Da mesma forma, pelo socorro e cuidados à minha coluna, agradeço a minha querida e competente fisioterapeuta, Michelle Pontes, que me permitiu recuperar fôlego suficiente para estar em pé, me centrar, trabalhar e equilibrar relacionamentos de todas as naturezas. Você chegou no momento certo e tem sido valiosa!

Na estruturação deste tipo de trabalho muitos são os detalhes e quase infinitas as tarefas que passo a passo configuram o que chamamos de tese. Por isso, passo agora à lista dos agradecimentos aos auxílios operacionais e materiais: 
- antes dos demais, agradeço aos educadores(as), que muito amavelmente me receberam e se disponibilizaram a ceder seu escasso tempo para compartilhar um pouco de seu aprendizado sobre a vida;

- agradeço o apoio na transcrição das 28 fitas cassete de entrevistas, que recebi de Flávio Amaral, Kathy Homonnay (minha mãe), Aline Dalsgaard, Renata Ferreira, Daniel Corrêa, Alba Cardoso e Roseane Delgado.

- foi indispensável o amparo, nos momentos em que necessitei de traduções, oferecido por minha irmã Elisa, por minha mãe, por meu pai, pelo amigo Renzo Rocha e pela amiga Ana Paula Wauke.

- fico especialmente grata pela acolhida carinhosa e generosa todas as vezes que precisei ir ao Rio para concluir alguma etapa do trabalho que me exigia a presença física ali. Sem o apoio de Tereza Ribeiro, Letícia Schelb, Fernanda Insfrán, Pedro Halbritter e dos manos Régis e Leonel Tractenberg, as entrevistas, pesquisas de biblioteca, reuniões de orientação teriam sido mais difíceis e custosas.

- fundamental foi a solidariedade dos amigos Rafael Franco - que me emprestou um monitor quando o meu queimou - Antonio Fontenelle e Renzo Rocha, que providenciaram um laptop para a fase final da tese, quando necessitei ter maior mobilidade para complementação das pesquisas e para a redação. Nos últimos dias da escrita ainda contei com o presente inesperado de um novo monitor, desta vez LCD. Família, obrigada!

- preciosas foram as involuntárias e voluntárias dicas de leitura de Waldo Vieira, Tomas Heidt, Alexandre Zaslavski, Ione Basílio, das irmãs psi Cristiane e Tânia Ferraro e da amiga de todos os momentos, Eloiza Neves.

- e, claro, imprescindíveis as inspiradas conversas e reflexões acerca do tema, especialmente com Thais Lima, Michelle Pontes, Paulo Abrantes, Cristiane e Tânia Ferraro, cujas experiências me foram exemplares. 
- pela busca e envio de livros não encontrados em Foz do Iguaçu, obrigada Elisa e Paola. E obrigada a Thais Lima, Ana Paula Wauke, Ana Paula Abreu, Daniel Corrêa e Daniela Seabra por tentarem encontrá-los nas bibliotecas universitárias de Foz.

- por formatar o texto, sou grata a Daniel Corrêa.

- A Eloiza e à secretaria (EDU), pelos procedimentos finais de entrega da tese.

Aos muitos amigos que permaneceram próximos, estando em Foz, São Paulo, Rio, ou mesmo mais longe, enquanto meu pai se recuperava da cirurgia. Agradeço especialmente a Maludy Pekin, amparadora de primeira hora nos socorros a meu pai e a Áurea Andriolo, amiga de excepcional solidariedade e presença. E muito especialmente a Elisa.

Aos meus companheiros de convivência doméstica mais próximos, a amiga Ana Paula Wauke e Daniel Corrêa. Pela paciência e ajuda na organização da vida prática, contribuindo para reverter tempo para a escrita.

Aos franceses, ingleses, chineses, italianos, gregos e alemães, cujas peculiares formas de pensar propiciaram maior percepção de mim mesma, de minhas raízes, das diretrizes de meu trabalho e de aspectos seus que andam a requerer renovação. A identificação destas afinidades remodelou e ampliou minha atuação existencial no esforço pela organização/ construção de uma sociedade mais lúcida e saudável. Recuperar a memória de aprendizados e valores possibilita escolhas mais acertadas.

Por fim, agradeço à CAPES por ter viabilizado através do programa de bolsas estes quatro anos de estudo, incluindo a participação em congressos e eventos de intercâmbio. 
In memorian: mesmo após sua passagem faço questão de reiterar minha gratidão ao Floriano, pela confiança no trabalho e por me propiciar a oportunidade de inserção na UDC, faculdade que me recebe agora ao finalizar a tese. 


\section{Resumo}

Ribeiro, Luciana Mello. Professores universitários: seus valores e a opção pela Educação Ambiental. Rio de Janeiro, 2008. 309p. Tese de Doutorado - Departamento de Educação, Pontifícia Universidade Católica do Rio de Janeiro.

A Educação Ambiental (EA), um novo paradigma educacional, vem enfrentando uma série de desafios em seu processo de institucionalização no Brasil e no mundo, nestes seus pouco mais de 30 anos de trajetória. Desde 1999, a Lei Nacional de EA garante a obrigatoriedade de sua difusão em todas as instâncias sociais, seja nos meios de comunicação, nas empresas, no campo, ou em cada nível do ensino formal. Sua natureza interdisciplinar fez com que se propusesse incorporá-la de modo transversal nos processos educativos. Considerando as dificuldades de ordem cultural, burocrática, política, e mesmo psicológicas e sociais, tal proposição, com todos os avanços que se fez, segue ainda distante do horizonte desejado. A universidade, idealmente, deveria ser um dos locus transformadores da realidade, já que se propõe ser um espaço para formação educacional em diversos sentidos. Entretanto, sendo tradicionalmente conservadora em termos de práticas, não manifesta situação melhor quanto à EA. Ainda assim, existem docentes universitários que arrostam as dificuldades e desenvolvem práticas educativo-ambientais de fato engajadas e transformadoras. O que os motiva e mobiliza nesse sentido é a questão que orientou esta pesquisa. Tomou-se por hipótese serem os valores pessoais o fator decisivo nesta opção. Neste caso, que meios e experiências morais teriam produzido tais valores? De que forma? Como se expressam? Em busca de entender esta motivação lançou-se mão da história oral, através de sua modalidade conhecida por depoimentos pessoais, colhidos estes por meio de entrevistas. Mesclando memórias, práticas cotidianas e escolhas, a entrevista percorreu a trajetória pessoal e profissional destes docentes, procurando ir além da mera teorização em torno de valores desejados. Assim, foram confrontadas a prática e os ideais de cada docente, sendo tomados por indicadores de alinhamento entre discurso e valores a coerência e a vergonha. A riqueza dos relatos indica forte relação entre os valores principais de cada professor e sua prática social. Em comum, tais professores têm um perfil idealista e gosto pela vida, valorizando a justiça, a solidariedade, a gratidão, a relação humana e a responsabilidade, elementos aos quais conseguem dar corpo 
através de grande engajamento e dedicação ao trabalho, entendido e buscado enquanto meio de realização de seu projeto de vida. Idéias inatas, experiências familiares, sócio-culturais e educativas parecem ter contribuído para as escolhas existenciais dos docentes estudados. Espera-se que a identificação destes perfis e experiências formadoras possa inspirar a criação de processos educativos, iniciais ou continuados - tendo em vista a generalização do saber ambiental e do sujeito ecológico. Pretende-se, por fim, que a presente tese venha a contribuir para o debate acerca do processo pedagógico formador de valores no âmbito da Educação Ambiental.

\section{Palavras-chave}

Educação ambiental, docentes universitários, depoimentos pessoais, instituições de ensino superior, valores, projeto de vida, formação profissional, sociedades sustentáveis. 


\section{Abstract}

Ribeiro, Luciana Mello. University Professors: their values and the option for the Environmental Education. Rio de Janeiro, 2008. 309p. PhD Thesis - Departamento de Educação, Pontifícia Universidade Católica do Rio de Janeiro.

Environmental Education (EE), a new educational paradigm, has been facing several challenges during its institutionalization process in Brazil and in the world over its thirty years trajectory. Since 1999, the Brazilian EE National Law made mandatory its diffusion in every social instance, such as the media, enterprises, countryside municipalities, and within each formal education level. The EE interdisciplinary nature has indicated its inclusion through a transversal approach within educational processes. Considering the difficulties within cultural, bureaucratic, politic and even psychological and social instances, such proposition continues - besides many developments achieved -, far from its goal. The institution of higher education, ideally, should be a social changing locus, as it has the purpose of being a place for educational development in many ways. However, being traditionally conservative within its practices, it is not doing well concerning EE. Even so, there are professors whom, despite difficulties, develop educative-environmental practices truly committed with social change. The reasons which motivate and mobilize them in this direction are the key matter that guided this research. By hypothesis, this work proposes that personal values are decisive factors leading these university teachers into this option. In this case, what means and moral experiences have produced such values? How was it? How are they regularly expressed? In order to understand their motivation it was applied the oral history research approach through personal depositions, obtained through interviews. Mixing memories, daily practices, and choices, the interviews explore university teacher's personal and professional trajectory, trying to proceed beyond simple theorizations about required values. Furthermore, their practice and educational ideals were compared, being taken the coherence and the shame as alignment indicators between their speeches and values. A large quantity of stories indicates a strong relation between the main values of each teacher and their social practice. Yet, as a common characteristic, such professors share an idealistic profile and taste for life, valuing justice, solidarity, gratitude, human 
relationship and responsibility, elements which they develop by great commitment and dedication to work, understood and pursued as life project accomplishments. Innate ideas, family background, educational and social-cultural experiences also seem to have contributed to the life choices of our research's participants. It is expected the investigation of these personal profiles and experiences may inspire the development of learning processes, within initial or further education levels, in order to disseminate the Environmental Knowledge and the Ecological Subject matter. It is intended, ultimately, this thesis can contribute to the discussion about value-maker pedagogical processes within the Environmental Education field.

\section{Key-words}

Environmental education, university teachers, institution of higher education, personal depositions, values, life project, professional development, sustainable societies. 


\section{Sumário}

1 Introdução

2 Constituição e Instituição da Educação Ambiental 26

2.1. O enraizamento 29

2.1.1. O terceiro setor 32

2.1.2. O meio empresarial 33

2.1.3. Os meios de comunicação de massa 34

2.1.4. O campo ambiental, o sujeito ecológico e o contexto da pesquisa 34

2.2. A universidade educando ambientalmente: como anda este processo

3 Implicações pedagógicas da Educação Ambiental 54

3.1. A consciência moral 62

$\begin{array}{ll}\text { 3.2. Valores na educação ambiental } & 71\end{array}$

4 Sobre a natureza dos valores $\quad 78$

4.1. Ética e moral $\quad 78$

4.2. Aspectos históricos do estudo dos valores 82

4.2.1. Na filosofia

4.2.2. Na psicologia social $\quad 85$

4.3. Definindo valores: tipos e estrutura 92

4.4. A percepção de valor 108

4.5. A faculdade de apreciar ou o ato de dar valor 109

4.6. Valores enquanto sistema 112

5 Estrutura da pesquisa 117

5.1. Delimitação do problema 119

5.2. Estratégias e público a pesquisar 122

5.3. Critérios de escolha 131

5.4. Indicadores 132 
6 Os entrevistados(as): quem são, o que querem e como vivem

6.1. Caracterização

6.2. As entrevistas

137

6.3. Análise dos dados

138

6.3.1. Os entrevistados(as): quem são 140

6.3.2. Os entrevistados(as): o que querem 141

6.3.2.1. Projetos de vida: opção pela EA 141

6.3.2.2. Projetos de vida: efeitos do trabalho 152

6.3.2.3. Projetos de vida: mudanças no mundo 158

6.3.2.4. Projetos de vida: comportamento 160

6.3.2.5. Projetos de vida: perspectivas 162

6.3.3. Os entrevistados(as): como vivem 164

6.3.3.1. Práticas existenciais: valores em operação 164

6.3.4. Uma palavra sobre os meios de experiência moral 192

7 Utopias: por uma proposta de sociedades sustentáveis 202

7.1. Recapitulando... 202

7.2. A EA enquanto estratégia utópica 203

7.3. Ensinar valores? A universidade como espaço formador 205

7.4. Para formar educadores ambientais/ a pessoa construtora da utopia sustentabilista

9 Referências Bibliográficas 226

9.1. Webgrafia 232

9.2. Apêndices 233

9.2.1. A1 - Roteiro de entrevista 233

9.2.2. A2 - Mini-Inventário Pessoal: (roteiro de auto-observação) 235

9.2.3. A3 - Lista de Siglas 236

9.2.4. A4 - Lista de Quadros 238

9.2.5. A5 - Lista de llustrações 239

9.2.6. A6 - Lista de Esquemas 240 
Acho que os sentimentos se perdem nas palavras. Todos deveriam ser transformados em ações, e em ações que tragam resultados.

Florence Nightingale 